\title{
Impact of Mass Chemotherapy Filariasis Control Programme on Soil-Transmitted Helminth Infections in Sri Lanka
}

\author{
NR de Silva1 ${ }^{1}$, A Pathmeswaran ${ }^{2}$, SD Fernando ${ }^{3}$, CR Weerasinghe ${ }^{1}$, RR Selvaratnam ${ }^{1}$, EA \\ Padmasiri $^{4}$, and A Montresor ${ }^{5}$ \\ ${ }^{1}$ Departments of Parasitology, University of Kelaniya \\ ${ }^{2}$ Community Medicine, Faculty of Medicine, University of Kelaniya \\ ${ }^{3}$ Dept of Parasitology, Faculty of Medicine, University of Colombo \\ ${ }^{4}$ WHO-SEARO, New Delhi, WHO Headquarters, Geneva \\ ${ }^{5}$ Parasite and Vector Control Division, WHO Headquarters, Geneva
}

The WHO's Global Programme to Eliminate Lymphatic Filariasis aims to stop the spread of infection and to alleviate the suffering of individuals affected by lymphatic filariasis. The strategy is based on a Mass Drug Administration (MDA) programme that uses two drugs (diethylcarbamazine citrate (DEC) or ivermectin, plus albendazole), annually, for 4-6 years, for entire populations at risk of infection with lymphatic filariasis. Inclusion of albendazole in this two-drug treatment regimen is expected to result in a public health impact beyond lymphatic filariasis alone, largely because of its effectiveness against soiltransmitted helminth (STH) infections. Anticipated health benefits include nutritional benefits (such as height and weight gains and reduction of anaemia), greater cognitive development among children, and greater productivity in the adult population (Ottesen et al, 1999).

The MDA programme for elimination of lymphatic filariasis in Sri Lanka was launched in 1999. Initially only DEC was given, twice a year. This was changed to the annual two-drug regimen in $2001-2$. Transmission of lymphatic filariasis is largely confined to the western and southern coastal belt (Figure 1), but STH infections are endemic in varying degrees throughout the country (Fernando \& Balasuriya 1976, Nageswaran \& Sivarajah 1986, Wijesundera et al 1993, Sorensen et al 1996, de Silva 1997). This study was carried out to assess the impact of introducing albendazole in the national filariasis control programme, on STH infections. In order to do this, the prevalence and intensity of STH infections was assessed in an area known to be endemic for both STH and lymphatic filariasis, before and after introduction of albendazole.

The study was carried out in the Ragama Medical Officer of Health area, which lies within the Gampaha District of the Western Province and has a population of approximately 70,000 persons. Examination of stool samples from $200-250$ primary school children is

Author for correspondence: Prof NR de Silva, Dept of Parasitology, Faculty of Medicine, P. O. Box 6, Ragama, Sri Lanka, nrdes@ sltnet.lk, tel: +94 1 958219, fax: +94 1958337. 
recommended for assessment of the prevalence and intensity of STH infection in a given, ecologically homogenous area (Montresor et al 2002). In order to achieve this sample size, six schools were selected in a random stratified manner. Two were selected from among four schools with a student population of $<200$ and the rest from among the 10 larger schools in the area. Smaller schools generally serve poor communities, which are more likely to have a higher prevalence of STH. In the six selected schools, children in the year 3 classes (8-year olds) were examined during the baseline survey in March and May 2002, while children in year 4 (9-year olds) were examined during the follow-up survey in September and October 2002. The Ministry of Health carried out its MDA programme in July 2002: drugs were delivered to each household by volunteers on a designated date. The survey team visited each school, carried out a short educational activity relating to intestinal nematodes, and distributed labelled containers for stool samples. The samples were collected the next morning and all children in the selected classes were given a tablet of generic mebendazole (500mg). Stool samples were examined the same morning, using the Kato-Katz technique (WHO, 1991). Data were entered on Epi Info Version 6.03 and statistical analysis was carried out on Epi Info and Stata Version 5. 95\% Confidence Intervals (C.I.) were constructed on the intervention effects: reduction in prevalence using exact methods, and reduction in intensity of infection using negative binomial regression.

During the baseline survey, samples were returned by $265 / 360$ (73.6\%) children in the selected population and by 252/397 (63.5\%) during the follow-up survey. Overall, there were equal numbers of boys and girls in both baseline ( $49.9 \%$ boys) and follow-up (50.0\% boys) surveys. $89.4 \%$ of the children in the initial survey were 8 -year olds, and $84.7 \%$ of the children in the follow-up survey were 9 -year olds. The prevalence rates were less than $5 \%$ for all 3 species (Table 1). Trichuriasis was the commonest infection in both surveys (4.1\% and $1.6 \%$ ), followed by ascariasis. The prevalence of hookworm (probably Necator americanus, the only species found in Sri Lanka) was negligible. The cumulative prevalence of STH infection, i.e. the percentage of individuals infected with one or more STH, was $4.5 \%$ at baseline and $2.0 \%$ at follow-up. In the baseline survey, the overall prevalence of helminth infection was highest in the Ihalagama Primary School $(6 / 24,25 \%)$, whereas prevalence was highest in the Polpitimukalana Primary School $(1 / 8,12.5 \%)$ at follow-up. Both are small schools with less than 200 students on the school registers. Compliance with the filariasis MDA programme was high: 216 of 252 (85\%) children examined in the followup survey (or their mothers) said they had taken the DEC-albendazole combination in July.

The species prevalence and cumulative prevalence rates declined from baseline to follow-up surveys but the differences were not statistically significant. The mean egg counts also declined from baseline to follow-up. The reduction in mean egg counts, based on negative binomial regression analysis adjusted for sex and school, was more than $99 \%$ for all three infections (see Table 2). As for the prevalence rates, these reductions were also not statistically significant because of the small numbers involved.

The pattern of low cumulative prevalence, with predominant trichuriasis, is usually seen in communities that have been exposed to repeated anthelmintic chemotherapy. Residual trichuriasis often occurs because the parasite is notoriously unresponsive to treatment even with the most effective broad-spectrum anthelmintics (de Silva et al 1997). The low 
prevalence of STH infection is consistent with other recent reports on STH infections in the area (de Silva et al, 1996a, Udayani et al, 1999), in marked contrast with the situation in 1962 when the overall prevalence rate was 80.6\% (WHO 1966). Researchers in other parts of the country have also noted declining prevalence rates during the last decade (de Silva et al 1996b, de Silva 1997, Amarasinghe \& Weerasooriya 1999) in areas that previously had high transmission. This decline, which has occurred in the absence of a national control programme that specifically targets STH infections, is probably due to regular treatment of children by their parents with inexpensive, broad-spectrum anthelmintics such as mebendazole.

Although the decreases were not statistically significant, inclusion of albendazole in the filariasis control programme probably did result in a decline in the prevalence and intensity of STH infections in the study population. However, because prevalence rates and intensities were very low even at baseline, it is unlikely that the decline will have an impact on the health status of the community as a whole. On the other hand, it seems probable that during the lifespan of the filariasis control programme, STH infections will be further reduced, or even eliminated, in all areas where the MDA programme is carried out in Sri Lanka.

As helminth control programmes are added to the public health activities of developing countries, the problem of evaluating programme efficacy at low levels of transmission will occur with increasing frequency. When prevalence rates are very low, as found by us, in order to demonstrate a statistically significant decline in prevalence rates, or even in intensity of infection, it becomes necessary to have a much larger sample size than the usual $200-250$ individuals currently recommended by the WHO. This raises the issue of costbenefit: in a resource-strapped developing country, is it worth incurring the extra expense of examining such large numbers, when the impact of these infections on general morbidity and mortality is likely to be negligible?

\section{Acknowledgements}

This study was supported by the World Health Organization. We thank all the principals, teachers and children in the schools selected for the study, for their willing co-operation, Drs J Abhayaratne, C Mohottiarachchi and G Perera for assistance in sample collection, Mr H Sudusinge and Mr S Abeysundara for technical assistance. We also wish to thank the referees for helpful comments.

\section{References}

Amarasinghe Y, Weerasooriya MV. Prevalence of intestinal parasites in an urban slum community in Matara. Galle Medical Journal. 1999; 11:1-6.

de Silva H. Childhood intestinal infections in Sri Lanka. Galle Medical Journal. 1997; 1:70-80.

de Silva NR, Kodituwakku KKAP, Edirisinghe SS, de Silva HJ. Routine use of mebendazole in pregnancy. Ceylon Medical Journal. 1996a; 41:99-101. 1996. [PubMed: 8917969]

de Silva NR, Jayapani VPP, de Silva HJ. Socioeconomic and behavioural factors affecting the prevalence of geohelminths in preschool children. Southeast Asian Journal of Tropical Medicine \& Public Health. 1996b; 27:36-42. 1996. [PubMed: 9031397]

de Silva N, Guyatt H, Bundy D. Anthelmintics: a review of their comparative clinical pharmacology. Drugs. 1997; 53:769-788. [PubMed: 9129865]

Fernando MA, Balasuriya S. Prevalence of soil-transmitted helminths in the Hindagala Community Health Project area. Ceylon Medical Journal. 1976; 22:177-183. 
Montresor, A., Crompton, DWT., Gyorkos, TW., Savioli, L. Helminth control in school-age children: a guide for managers of control programmes. Geneva: World Health Organization; 2002.

Nageswaran C, Sivarajah N. Intestinal parasitic infestations in children living in the underprivileged sector of Jaffna Municipality. Jaffna Medical Journal. 1986; 21:23-28.

Otteson EA, Ismail MM, Horton J. The role of albendazole in programmes to eliminate lymphatic filariasis. Parasitology Today. 1999; 15(9):382-386. [PubMed: 10461168]

Sorensen E, Ismail M, Amarasinghe DKC, Hettiarachchi I, Dassenaieke TSdeC. The prevalence and control of soil-transmitted nematode infections among children and women in the plantations in Sri Lanka. Ceylon Medical Journal. 1996; 41:37-41. [PubMed: 8771940]

Udayani WI, Uduwevidane IK, Uvais AL, Wanniarachchi SL, Warnakulasuriya SN, de Silva NR. Intestinal helminth infections among children in a slum community in Enderamulla. Ceylon Medical Journal. 1999; 44:187-188. [PubMed: 10895277]

Wijesundera, MdeS, de Silva, NR., Ariyaratne, CA. Prevalence patterns of intestinal parasitoses in schoolchildren in Mahaweli System C, a new settlement in Sri Lanka. Kandy Medical Journal. 1993; 2:5-9.

World Health Organization Diarrhoeal Diseases Team. Diarrhoeal Diseases. WHO; 1966. Unpublished Documents WHO / ENT / 66.4

WHO. Basic laboratory methods in medical parasitology. Geneva: World Health Organization; 1991. 


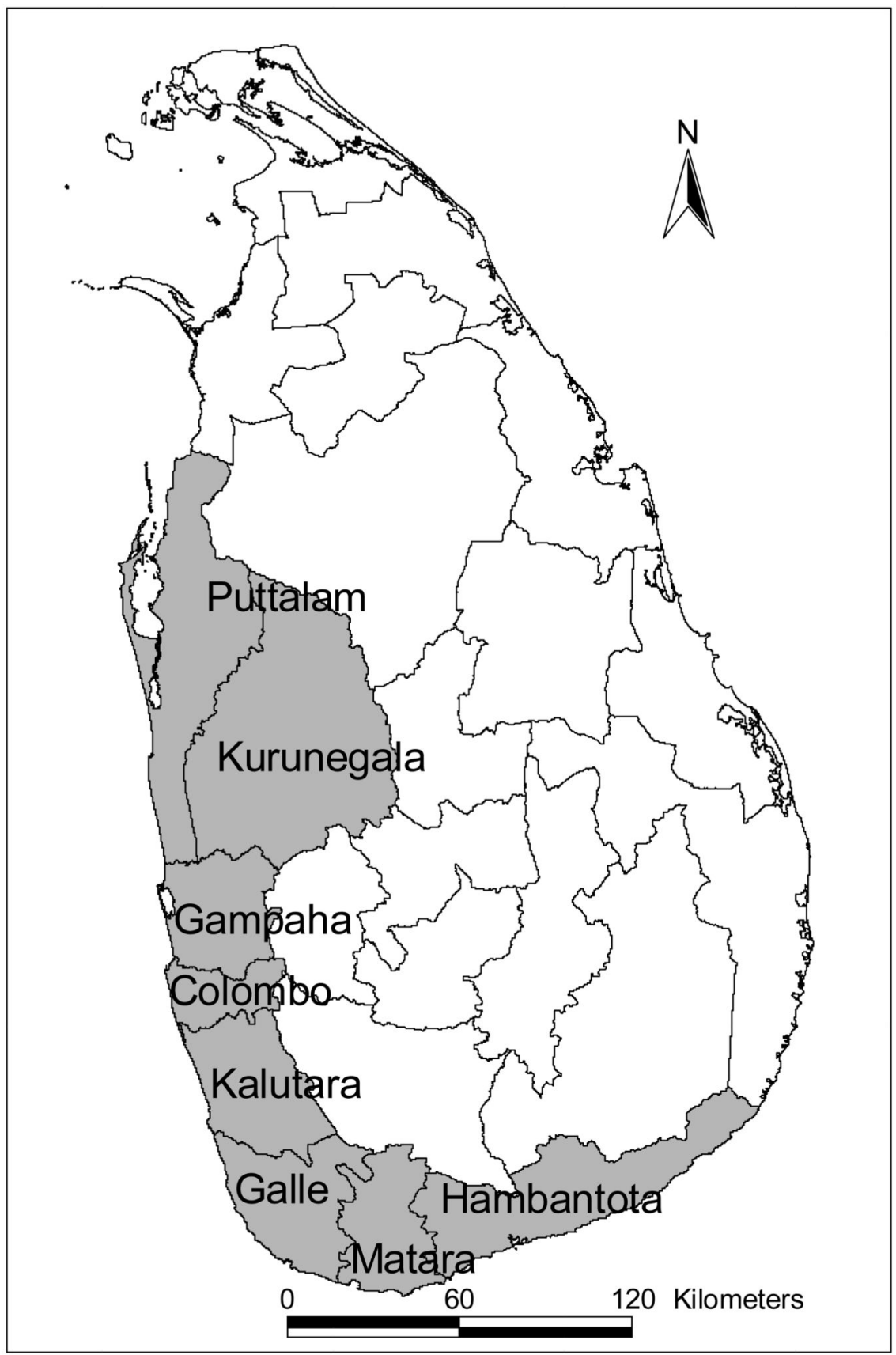

Figure 1.

Districts with endemic filariasis in Sri Lanka 


\section{Table 1}

Species and cumulative prevalence rates in baseline and follow-up surveys

\begin{tabular}{lrrr}
\hline & $\begin{array}{r}\text { Baseline survey } \\
\text { Number infected } \\
\text { (prevalence) n=265 }\end{array}$ & $\begin{array}{r}\text { Follow-up survey } \\
\text { Number infected } \\
\text { (prevalence) n=252 }\end{array}$ & $\begin{array}{r}\text { Reduction in prevalence } \\
\text { baseline - follow-up } \\
\text { (95\% C. I.) }\end{array}$ \\
\hline Ascaris lumbricoides & $2(0.75 \%)$ & $1(0.4 \%)$ & $0.36(-0.94$ to +1.66$)$ \\
Trichuris trichiura & $11(4.1 \%)$ & $4(1.6 \%)$ & $2.56(-0.29$ to +5.42$)$ \\
Hookworm & $2(0.75 \%)$ & 0 & $0.75(-0.29$ to +1.80$)$ \\
Enterobius vermicularis & 0 & $2(0.8 \%)$ & $-0.80(-1.89$ to +0.30$)$ \\
Cumulative & $12(4.5 \%)$ & $5(2.0 \%)$ & $2.50(-0.49$ to +5.58$)$ \\
\hline
\end{tabular}




\section{Table 2}

Intensity of STH infections in baseline and follow-up surveys

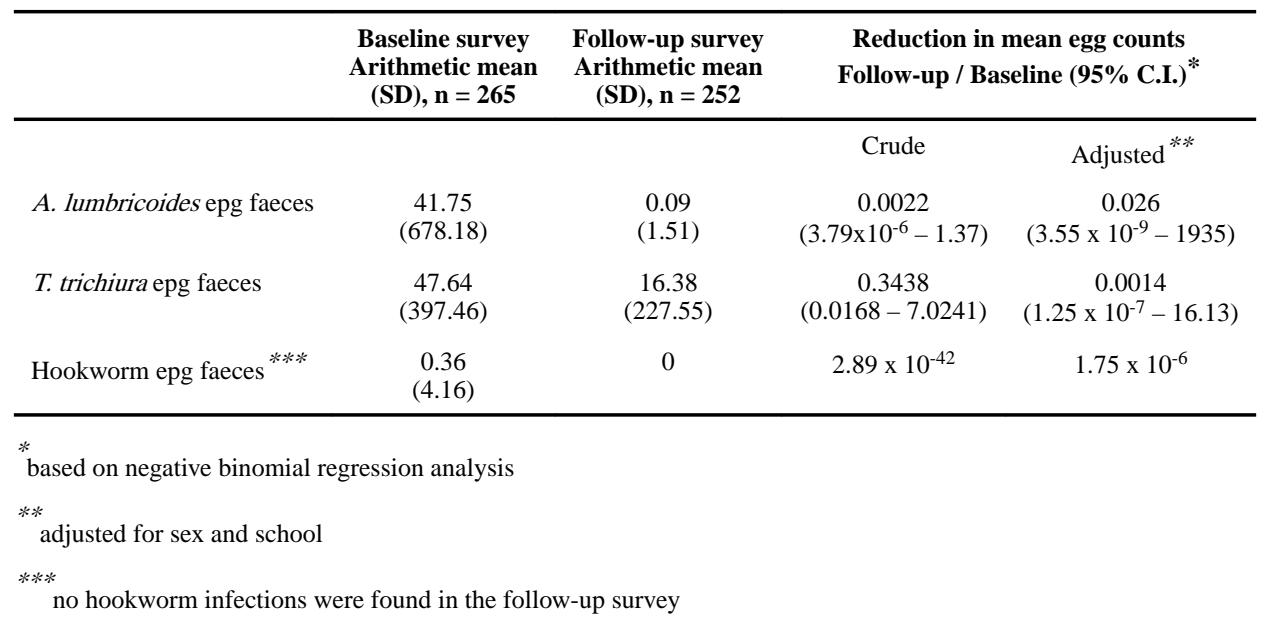

